OPEN ACCESS

Edited by:

Angelina Pilatti,

Consejo Nacional de Investigaciones

Científicas y Técnicas (CONICET),

Argentina

Reviewed by:

Julia Elizabeth Cohen-Gilbert,

McLean Hospital, United States

Ty Brumback,

Northern Kentucky University,

United States

*Correspondence:

Samuel Suárez-Suárez

samuel.suarez@usc.es

Specialty section:

This article was submitted to

Addictive Disorders,

a section of the journal

Frontiers in Psychiatry

Received: 04 February 2020

Accepted: 26 May 2020

Published: 09 June 2020

Citation:

Suárez-Suárez S, Doallo $S$,

Pérez-García JM, Corral M, Rodriguez Holguín $S$ and Cadaveira F (2020) Response Inhibition and Binge

Drinking During Transition to

University: An fMRI Study.

Front. Psychiatry 11:535.

doi: 10.3389/fpsyt.2020.00535

\section{Response Inhibition and Binge Drinking During Transition to University: An fMRI Study}

\section{Samuel Suárez-Suárez *, Sonia Doallo, Jose Manuel Pérez-García, Montserrat Corral, Socorro Rodríguez Holguín and Fernando Cadaveira}

Department of Clinical Psychology and Psychobiology, Universidade de Santiago de Compostela, Santiago de Compostela, Spain

Background: Binge Drinking (BD), a highly prevalent drinking pattern among youth, has been linked with anomalies in inhibitory control. However, it is still not well characterized whether the neural mechanisms involved in this process are compromised in binge drinkers (BDs). Furthermore, recent findings suggest that exerting inhibitory control to alcohol-related stimuli requires an increased effort in BDs, relative to controls, but the brain regions subserving these effects have also been scarcely investigated. Here we explored the impact of $\mathrm{BD}$ on the pattern of neural activity mediating response inhibition and its modulation by the motivational salience of stimuli (alcohol-related content).

Methods: Sixty-seven (36 females) first-year university students, classified as BDs ( $\mathrm{n}=$ 32) or controls ( $n=35$ ), underwent fMRl as they performed an alcohol-cued Go/NoGo task in which pictures of alcoholic or non-alcoholic beverages were presented as Go or NoGo stimuli.

Results: During successful inhibition trials, BDs relative to controls showed greater activity in the bilateral inferior frontal gyrus (IFG), extending to the anterior insula, a brain region usually involved in response inhibition tasks, despite the lack of behavioral differences between groups. Moreover, BDs displayed increased activity in this region restricted to the right hemisphere when inhibiting a prepotent response to alcohol-related stimuli.

Conclusions: The increased neural activity in the IFG/insula during response inhibition in BDs, in the absence of behavioral impairments, could reflect a compensatory mechanism. The findings suggest that response inhibition-related activity in the right IFG/insula is modulated by the motivational salience of stimuli and highlight the role of this brain region in suppressing responses to substance-associated cues.

Keywords: binge drinking, response inhibition, Go/NoGo, fMRI, alcohol-related stimuli 


\section{INTRODUCTION}

Alcohol is by far the most used drug among youth in Western countries, as informed in epidemiological reports by the ESPAD (European School Survey Project on Alcohol and Other Drugs) (1) and the SAMSHA (Substance Abuse and Mental Health Services Administration) (2). The actual consumption rate of this substance entails significant health and economic costs $(3,4)$ and is one of the main causes of death among young people and adolescents (4). In this regard, multiple studies have indicated that the age of onset of drinking may be a determining factor in the development of future alcohol use disorders (AUD), illicit drug dependence and different problem drinking patterns (5-9). For example, Hingson et al. (8) informed that an early drinking onset significantly increases the probability to engage in binge drinking (BD). This pattern of consumption, characterized by the intake of large amounts of alcohol in a short period of time (leading to a blood alcohol concentration of at least $0.08 \mathrm{~g} / \mathrm{dl}$ ) [National Institute on Alcohol Abuse and Alcoholism (NIAAA), (10)], has been linked to neural and neuropsychological anomalies (11-13) and it could be considered as an initial step for developing alcohol use disorders (7, 14, 15). Moreover, evidence from animal (16) and human (17) studies about the vulnerability of the adolescent brain to the neurotoxic effects of alcohol highlights the impact of alcohol consumption on brain development. Of particular concern is the upsurge in alcohol consumption that takes place once the legally allowed age is exceeded (i.e. 18-21 years in most countries) but brain maturation is still under development $(18,19)$. In this regard, previous studies have demonstrated that brain regions known to support cognitive control, such as the prefrontal cortex, mature late $(20,21)$ and are particularly vulnerable to the neurotoxic effects of alcohol consumption $(22,23)$. University students have been specifically identified as a population of interest, mainly due to the escalation in alcohol drinking and increased rates of $\mathrm{BD}$ during transition to university $(24,25)$, placing them in a vulnerable position to develop future AUD (15).

Neuroscientific models of addictive behaviors have proposed that impairments of two related processes-response inhibition and salience attribution-may underlie the development of substance use disorders (26-29). In line with dual-process models, evidence of an imbalance between impaired response inhibition and an increased impact of the motivational properties of drug-related stimuli has been reported in alcoholdependent patients [for a review, see (30)]; however, less is known about this potential imbalance in young binge drinkers (BDs) [for a theoretical framework, see (31)].

Response inhibition, usually defined as the ability to withhold or suppress a prepotent response (32), is considered a key mechanism to adjust behavior to meet environmental demands. Different metaanalyses have revealed the involvement of a predominantly rightlateralized fronto-parietal network, including the inferior parietal lobule (IPL), inferior frontal gyrus (IFG), middle frontal gyrus (MFG) and anterior insula, in successful inhibition of responses (33-38), and have underlined the importance of the right inferior frontal cortex $(36,37,39)$.
An extensive body of work in alcohol dependence has shown alterations in inhibitory control at behavioral and neural levels [for a review, see (40); for a meta-analysis, see (41)]. Studies centered on young BDs have also provided evidence for the hazardous effects of this pattern of consumption on inhibitory control processes [for a review, see (42)], although its impact on the neural network subserving response inhibition is still not well characterized. In this regard, neuroimaging studies have reported an increased neural activity in BDs compared to controls during successful response inhibition trials [(43); see also (44)], as well as the recruitment of different brain regions during failed inhibitions (45), even in the absence of behavioral differences between the groups.

Regarding the enhanced salience attribution to drug-related stimuli in alcohol-dependent patients, a recent meta-analysis has revealed increased neural activity in brain regions implicated in incentive salience, reward processing and habit circuitry (e.g. dorsal striatum, prefrontal areas, anterior cingulate cortex and insula) (46). This study has also indicated the presence of differences between heavy and light drinkers in the activity of parietal and temporal regions (46). Regarding non-clinical BDs, fMRI studies that assessed alcohol cue reactivity and implicit positive associations towards alcohol cues reported similar results, showing greater neural activity in BDs in comparison with light drinkers in several incentive salience- and reward-related areas including, but not limited to, the anterior cingulate cortex, insula and dorsal striatum $(47,48)$. Furthermore, greater neural activity to alcohol-related pictures in some of these regions predicted increases in drinking and more alcohol- related problems in a group of college students who transitioned to heavy drinking during a year follow-up period (49).

In line with the findings mentioned above and the principles of dual-process models, one could expect to find greater response inhibition impairments to alcohol-associated stimuli in both individuals with AUD and BDs. Studies with alcoholdependent patients offer behavioral and neuroimaging evidence that supports this hypothesis. A recent systematic review indicates that patients with AUD tend to show increased recruitment of the inhibitory control neural network (comprising dorsolateral and ventrolateral prefrontal cortex) and the salience network (anterior cingulate, insula and IPL) during alcohol-related processing while showing decreased engagement of relevant brain networks during non-drugrelated processing (29). This potential imbalance has been, however, scarcely investigated in BDs, with the few published studies reporting, at a behavioral level, both the presence (50) and absence (51-55) of differences in the percentage of false alarms to alcohol-related stimuli, and with, to our knowledge, only one neuroimaging study trying to disentangle the subjacent neural mechanisms of these effects (56). In this work, Ames et al. (56), using a Go/NoGo task that required the inhibition of a prepotent response to alcohol images (NoGo stimuli), reported an increased neural activity in BDs, compared to controls, in regions involved in cognitive control (i.e. dorsolateral prefrontal cortex, anterior cingulate and anterior insula) during successful inhibition trials, in the absence of behavioral differences in the proportion of inhibitory errors. However, this study only 
included alcohol images as NoGo stimuli, and it is thus not possible to determine if the observed neural response pattern was specifically related to successful inhibition of response to alcoholrelated stimuli or to a more general response inhibition process.

Here, we performed event-related functional magnetic resonance imaging (fMRI) in first-year university students during an alcohol-cued Go/NoGo task with a twofold aim: (1) to investigate the association between $\mathrm{BD}$ and potential anomalies in inhibitory control, and (2) to examine whether response inhibition processes are affected by the motivational salience of stimuli (i.e. alcohol- or non-alcohol-related content). Based on previous findings (43), we hypothesized, first, that BDs, compared to controls, would show an increased activation during successful inhibition trials (independently of the type of stimulus) in brain areas commonly identified as involved in response inhibition, such as the IFG, anterior insula, MFG or the IPL $(33,35)$, in the absence of behavioral differences between groups. Second, in line with previous studies (56) we expected the pattern of neural activity mediating response inhibition to be modulated by the stimulus motivational value, reflected in increased engagement, in BDs relative to controls, of the response inhibition neural network when withholding a response to alcohol-related stimuli. At a behavioral level, based on previous findings (51-56) we did not expect to find any significant differences between groups in the proportion of inhibitory errors.

\section{MATERIALS AND METHODS}

\section{Participants}

Eighty-five first-year university students (18-19 years old) were selected to participate in the neuroimaging assessment within the framework of a broader research on consequences of BD among university students (for ERPs results, see 54). Initially, 2,998 firstyear students from the University of Santiago de Compostela (Spain) completed a classroom questionnaire assessing alcohol and other substance consumption, as well as sociodemographic information. This questionnaire included the adapted version of the Alcohol Use Disorders Identification Test (AUDIT) $(57,58)$, the short version of the Nicotine Dependence Syndrome Scale (NDSSS) $(59,60)$ and the Cannabis Abuse Screening Test (CAST) $(61,62)$. In order to identify the most suitable participants among the initial 2,998 questionnaires, the following preselection criteria were applied to the classroom questionnaire: i) provision of contact information (phone number and/or email); ii) 18-19 years old; and iii) nonconsumption of illegal drugs (except cannabis). From the initial 2,998 questionnaires, a total of 516 subjects were identified to meet these criteria and showed interest in participating in the study. These participants completed a semi-structured interview in which quantity and frequency of alcohol use over the past 180 days were assessed via the Timeline Follow-Back calendar (TLFB) (63). Additionally, those subjects who reported cannabis consumption at some time throughout their lives during the classroom questionnaire completed the Cannabis TLFB to assess their cannabis consumption over the past 90 days. Participants were also interviewed about personal and family history of psychopathological disorders and completed the Spanish version of the Symptom Checklist-90-Revised (SCL-90-R) (64) to ensure they met inclusion/exclusion criteria. Exclusionary criteria included the following: chronic medical conditions that could affect neurocognitive functioning (diabetes, hypothyroidism, liver diseases, etc.), history of neurological disorders or brain injury, personal history of DSM-IV-TR Axis I and/or II diagnosed disorders, a score above 90th percentile in the Global Severity Index (GSI) or in two or more symptoms dimensions of the SCL90-R, family history of major psychopathological disorders in firstdegree relatives (clinically diagnosed by a professional), family history of alcoholism or substance use disorders (at least two firstdegree relatives or three or more first- or second-degree relatives), AUDIT scores $>20$, use of psychoactive medications, use of illegal drugs (except occasional consumption of cannabis) in the last 6 months, non-corrected sensory deficits and MRI contraindications. All participants gave written consent and received monetary compensation for their participation.

Volunteers were classified as binge drinkers (BDs) if they reported one $\mathrm{BD}$ episode at least once a month for the last six months, or as controls $(\mathrm{CN})$ if they did not reach the alcohol consumption threshold for being considered BDs. Binge episodes were defined as the consumption of $\geq 50 \mathrm{~g}$ (female) or $\geq 70 \mathrm{~g}$ (male) of alcohol in one drinking occasion (i.e. an equivalent measure of the $4 / 5$ standard drinks criteria reported in the NIAAA's definition of BD) (10). Participants were instructed to abstain from consuming alcohol $24 \mathrm{~h}$ prior to the scan session.

Of the 85 subjects who met the inclusion criteria and completed the neuroimaging assessment, five participants were excluded from the analysis due to technical problems during image acquisition, seven participants were excluded due to excessive head movement during scanning (more than $3 \mathrm{~mm} /$ degrees of movement in any of the six directions), five were excluded for outlier behavioral data (more than $3 \mathrm{SD}$ above or below the group mean) and, lastly, one was excluded due to the presence of an artefact in the functional images. Hence, the final sample included 67 right-handed participants, with 32 BDs $(20$ females) and $35 \mathrm{CN}$ (16 females) (see Table 1 for complete demographic and alcohol use data).

\section{Behavioral Task}

During fMRI, participants completed a Go/NoGo task with pictures of alcoholic or non-alcoholic beverages as stimuli (see Figure $\mathbf{1}$ for

TABLE 1 | Demographic and substance use characteristics of the final sample (mean $\pm \mathrm{SD}$ ).

\begin{tabular}{|c|c|c|}
\hline & Controls & BDs \\
\hline$n$ (females) & $35(16)$ & $32(20)$ \\
\hline Age & $18.08 \pm 0.28$ & $18.22 \pm 0.42$ \\
\hline Caucasian (\%) & 100 & 100 \\
\hline Age of drinking onset ${ }^{\star \star \star}$ & $16.29 \pm 1.04$ & $15.22 \pm 1.24$ \\
\hline Total AUDIT score ${ }^{\star \star \star}$ & $1.94 \pm 2.52$ & $10.28 \pm 4.06$ \\
\hline 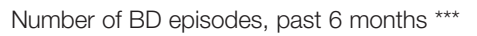 & $0.91 \pm 1.75$ & $22.91 \pm 12.26$ \\
\hline Average \# drinks per drinking occasion *** & $1.96 \pm 1.53$ & $6.78 \pm 1.98$ \\
\hline
\end{tabular}


illustration). The picture set was designed to include drinks representative of Spanish consumption habits, comprising active pictures that display beverages being served, opened or consumed, following similar criteria to the Amsterdam Beverage Picture Set (ABPS) (65). Forty-eight pictures displaying different alcoholic beverages (beer, wine, and spirits) were used as alcohol-related stimuli, whereas 48 pictures displaying water, juice, dairy and soft drinks were used as non-alcoholic stimuli. All pictures had the same background and were scanned at a similar resolution and image size.

Stimuli were presented using the software Presentation (version 16.3, Neurobehavioral Systems Inc., Albany, CA; http://www. neurobs.com/) and were delivered through MRI-compatible video goggles (VisualSystem, NordicNeuroLab, Bergen, Norway), with a resolution of $800 \times 600$ pixels. The task included two blocks of 168 images each (126 Go trials and 42 NoGo trials). Each picture stimulus was presented on a light gray background for $300 \mathrm{~ms}$ at the center of the screen followed by a long and variable inter-stimulus interval (ISI) lasting 2-12 s, during which only a fixation cross was displayed. The durations for the ISIs were drawn from a logarithmic distribution that was skewed toward the shorter intervals (50\% 2$4 \mathrm{~s}, 33 \% 4-8 \mathrm{~s}, 17 \%$ 8-12 s) (66). At the beginning of each block, participants were instructed to respond to one type of stimulus (Alcohol or Non-Alcohol), pressing a button with their right index finger on an MRI-compatible response grip (NordicNeuroLab, Bergen, Norway), as quickly as possible without making errors (Go trials), and to withhold their response to the other stimulus type (NoGo trials). Trial type (Go vs. NoGo) was randomized within each block and the order of blocks (Go Alcohol vs. Go NonAlcohol) was counterbalanced across subjects.

Participants received a practice session of the task before they entered the scanner. Once in the scanner, and prior to each block, participants were informed, through a 3-s instructions screen, about the type of stimulus to which they must respond (i.e. Go Alcohol or Go Non-Alcohol trials).

\section{Behavioral Analysis}

Reaction times (RTs) and the percentage of correct responses to Go stimuli, as well as the percentage of false alarms (FA) (i.e. response to NoGo stimuli), were submitted to $2 \times 2 \times 2$ mixedmodel analyses of variance (ANOVAs), with stimulus type (Alcohol, Non-Alcohol) as the within-subjects factor and group and gender as the between-subjects factors. Post-hoc comparisons were performed using the Bonferroni adjustment for multiple comparisons. All analyses were done with SPSS (version 21).

\section{fMRI Data Acquisition}

Functional images were collected with a 3T Achieva Philips body scanner (Philips Medical Systems, Best, NL) equipped with a 32channel SENSE head coil (located at the University Hospital Complex of Santiago de Compostela) using a $\mathrm{T} 2{ }^{\star}$-weighted echo-planar imaging sequence with the following acquisition parameters: $\mathrm{TR} / \mathrm{TE}=3000 / 30 \mathrm{~ms}$, flip angle $=87^{\circ}, \mathrm{FOV}=230 \times$ $230 \mathrm{~mm}$, voxel size $=3 \mathrm{~mm}^{3}, 45$ axial slices. The task was conducted in one run consisting of about 700 volumes $(\sim 35$ min). High-resolution anatomical T1-weighted images were also acquired using a $3 \mathrm{D}$ turbo field-echo sequence with the following parameters: $\mathrm{TR} / \mathrm{TE}=7.7 / 3.4 \mathrm{~ms}$, flip angle $=8^{\circ}, \mathrm{FOV}=240 \mathrm{~mm}$, voxel size $=0.8 \mathrm{~mm}^{3}, 200$ transverse slices, acquisition time $=7 \mathrm{~min}$.

\section{Image Processing and Analysis}

Imaging data were processed and analyzed using Statistical Parametric Mapping (SPM8; http://www.fil.ion.ucl.ac.uk/spm/ software/spm8/) implemented in Matlab (version 2015b, The Mathworks, Inc., Natick, MA). First, functional and anatomical images were reoriented to the anterior commissure. Then, functional images were corrected for slice timing and realigned and unwarped to correct for movement artefacts. The anatomical T1 images were coregistered to the realigned mean functional image, then images were transformed into standard MNI space using segmentation-based normalization parameters. The resulting functional images were spatially smoothed using a 7-mm FWHM Gaussian kernel. Blood oxygen level-dependent (BOLD) responses to each condition were modeled using an event-related design convolved with the canonical hemodynamic response function (HRF) to create regressors of interest (Go

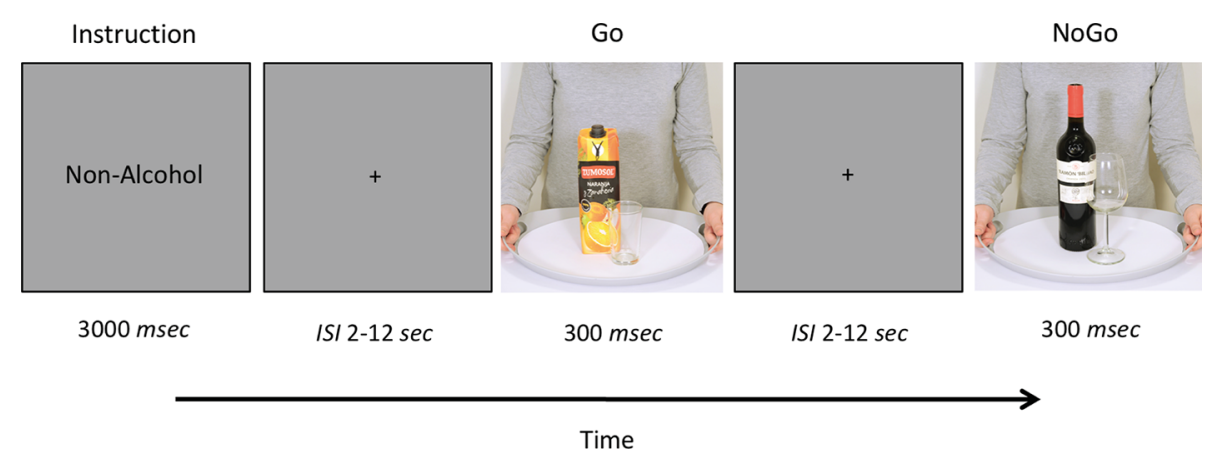

FIGURE 1 | Schematic representation of the Go/NoGo task. Participants completed a Go/NoGo task with pictures of beverages (with or without alcoholic content) as stimuli. The task consisted in two blocks of 168 trials (25\% NoGo trials). Before each block, participants were instructed to respond to one type of stimuli (Alcohol or Non-Alcohol) and to withhold their response to the other stimulus type. 
Alcohol, Go Non-Alcohol, NoGo Alcohol, NoGo Non-Alcohol). Instruction screens and response errors (i.e. failures to respond on Go trials or FA on NoGo trials) were modeled as effects of no interest. Additionally, movement parameters from the realignment step were included in the design matrix as regressors of no interest.

Individual $t$-contrasts were generated for each participant and then entered into a second-level random-effects analysis. Gender was included as a covariate in the analysis. We examined, first, the main effect for the response inhibition contrast (NoGo > Go) across all participants. The statistical threshold was set at $\mathrm{p}<.05$ family-wise error (FWE) corrected for multiple comparisons at the voxel level across the whole brain.

Secondly, two-sample t-tests were defined to determine the between-group effects (i.e. $\mathrm{BD}>\mathrm{CN}, \mathrm{BD}<\mathrm{CN}$ ). Given our $a$ priori hypotheses regarding differences in brain activity related to response inhibition (and its modulation by motivational salience), region of interest (ROI) analyses were conducted based on areas defined from a meta-analysis of Go/NoGo tasks involving complex stimulus identification (33) as follows: right IPL, right IFG, left IFG, right MFG, and right superior frontal gyrus (SFG) (see Supplementary Table 1 for a list of ROIs coordinates). Contrasts were initially thresholded at $\mathrm{p}<.005$ uncorrected and a cluster extent of 10 voxels; small volume correction (SVC) for multiple comparisons was then applied with a FWE-corrected threshold of $\mathrm{p}<.05$ at cluster level within $10 \mathrm{~mm}$-spheres centered on the reported coordinates after their transformation from Talairach into MNI space. To investigate the predicted higher BOLD activity in brain regions involved in response inhibition in $\mathrm{BDs}$ relative to $\mathrm{CN}$, we examined the contrast NoGo > Go. Next, we examined modulation of NoGo vs. Go trial activation by the alcohol- vs. non-alcohol-related stimulus content. Our prediction of greater engagement in BDs (vs. $\mathrm{CN}$ ) in areas mediating response inhibition when stimuli convey motivational salience was tested by a two-sample t-test comparing NoGo Alcohol > Go Non-Alcohol trials. To ensure that potential group differences in this contrast were directly linked to inhibiting responses to alcohol-related stimuli, and not simply due to general differences in inhibitory control processes, activation in NoGo Non-Alcohol > Go Alcohol trials was also explored. Finally, to test whether any observed activation differences between groups were due to overall differential reactivity to alcohol cues, we explored the contrast Alcohol > Non-Alcohol.

Additional Pearson's correlation analyses were performed between parameter estimates extracted from each ROI showing significant between-group differences and: i) the age at drinking onset; ii) the number of $\mathrm{BD}$ episodes in the last 6 months, as a measure of the intensity of the $\mathrm{BD}$ pattern.

\section{RESULTS}

\section{Behavioral Performance}

There were no significant differences between groups (BDs vs. $\mathrm{CN}$ ), neither in the response to Go stimuli (i.e. percentage of hits or RTs) nor in the number of commission errors (i.e. percentage of FA) to NoGo stimuli. A significant main effect of stimulus type for the percentage of hits $\left[\mathbf{F}_{(1,63)}=28.288, \mathrm{p}<.001\right]$ revealed greater accuracy for alcohol-related than for non-alcohol-related stimuli irrespective of the participant's consumption pattern. There was also a significant gender by group interaction for the percentage of correct responses to Go stimuli $\left[\mathbf{F}_{(1,63)}=7.59, \mathrm{p}=\right.$ $.008]$, which was explained by higher accuracy in males of the BD group $(95.57 \pm .96)$ relative to the $\mathrm{CN}$ group $(92.88 \pm .76)(\mathrm{p}=$ $.032)$, with no significant group differences in females (93.49 \pm .74 vs. $95.36 \pm .83 ; \mathrm{p}=.098)$. Behavioral data are summarized in Table 2.

\section{fMRI Results}

Whole-brain analysis for the whole sample revealed significant BOLD activations during successful inhibition (NoGo $>$ Go) in different areas of the right hemisphere including the precentral gyrus, IPL, IFG, MFG and SFG (see Table 3, Figure 2). These regions have been identified to be involved in Go/NoGo tasks in different meta-analysis (33-35). These results validate the ability of our task to tap into neural mechanisms related to response inhibition.

ROI analyses revealed significant differences between groups in BOLD response during successful response inhibition (NoGo > Go). Specifically, BDs showed greater activity, in comparison with $\mathrm{CN}$, in the bilateral BA47 (IFG extending to the anterior insula) during NoGo relative to Go trials (Table 4, Figure 3). Furthermore, the NoGo Alcohol > Go Non-Alcohol contrast revealed a significant increased activation in this region (BA 47), restricted to the right hemisphere, in BDs relative to the $\mathrm{CN}$ group, when inhibiting a prepotent response to alcoholrelated stimuli (Table 4, Figure 3). However, activations in the NoGo Non-Alcohol > Go Alcohol and Alcohol > Non-Alcohol contrasts did not reach statistical significance. This pattern of results suggests the modulation of the right IFG/insula activity to be specifically associated with suppressing responses to alcoholrelated stimuli. The ROI analysis did not show any significant regions of increased activity in $\mathrm{CN}$ compared with $\mathrm{BDs}$.

TABLE 2 | Behavioral data for Control and BD groups (mean \pm SD).

\begin{tabular}{lrrrrr}
\hline Behavioral Performance & \multicolumn{2}{c}{ Controls } & & \multicolumn{1}{c}{ Binge Drinkers } \\
\cline { 2 - 5 } & Alcohol & Non-Alcohol & Alcohol & Non-Alcohol \\
\hline Reaction Time (Go trials, ms) & $632 \pm 107$ & $642 \pm 100$ & $632 \pm 92$ & $916 \pm 86$ \\
\% Correct responses (Go trials) & $96.98 \pm 3.26$ & $91.04 \pm 5.88$ & & $96.53 \pm 4.84$ & $92.01 \pm 6.11$ \\
\% False alarms (NoGo trials) & $6.39 \pm 5.80$ & $6.94 \pm 6.69$ & $7.07 \pm 6.36$ & $7.66 \pm 6.27$
\end{tabular}


TABLE 3 | Regions activated at whole-brain analysis in the contrast NoGo > Go for the whole sample.

\begin{tabular}{|c|c|c|c|c|c|c|}
\hline Region (BA) & Side & $x(\mathrm{~mm})$ & $y(m m)$ & $z(m m)$ & $\mathbf{k}$ & $t$ \\
\hline Precentral/Postcentral Gyrus (4/3) & Right & 40 & -14 & 56 & 571 & 7.05 \\
\hline Precentral/Postcentral Gyrus (6) & Right & 60 & -10 & 38 & 108 & 6.74 \\
\hline Superior/Inferior Parietal Lobule (7) & Right & 32 & -54 & 52 & 237 & 6.59 \\
\hline Inferior Frontal Gyrus (47) & Right & 30 & 28 & -2 & 49 & 6.20 \\
\hline Middle Frontal Gyrus (9) & Right & 42 & 20 & 26 & 45 & 5.73 \\
\hline Superior Temporal Gyrus (22) & Right & 56 & -38 & 4 & 19 & 5.55 \\
\hline Superior/Middle Frontal Gyrus (9) & Right & 32 & 46 & 34 & 20 & 5.51 \\
\hline Superior Occipital Cortex/Precuneus (7) & Right & 26 & -84 & 28 & 33 & 5.47 \\
\hline
\end{tabular}

BA, Brodmann Area.

All results are significant at $p<.05$ whole-brain voxel-level FWE corrected and cluster size $(k) \geq 10$.

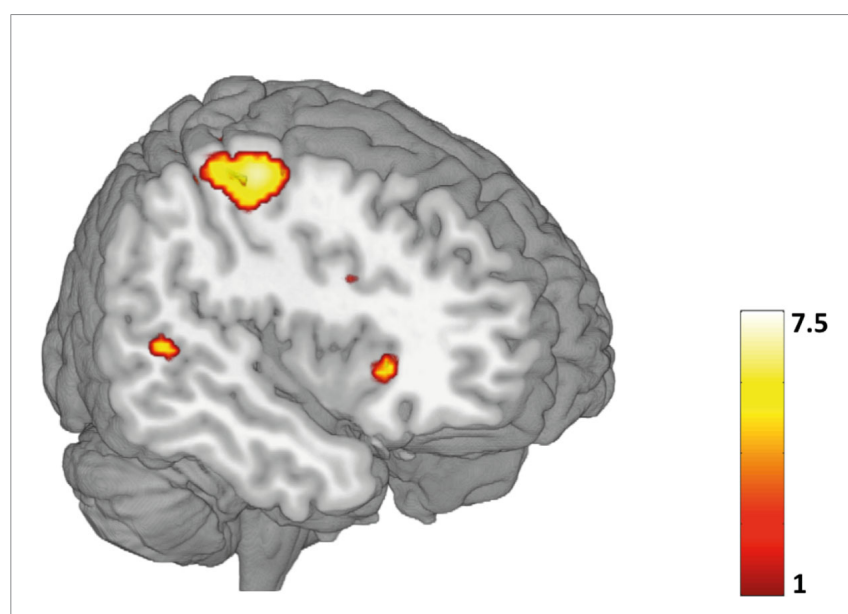

FIGURE 2 | Whole-brain task activation during correct inhibition (NoGo > Go) for the whole sample $(p<.05$, FWE corrected). Color bar represents t-values. A list of all significant activations for this contrast can be found in Table $\mathbf{3}$.

Correlation analysis performed in the BD group did not yield significant relationships (all $\mathrm{p}>.05$ ) with any of the variables explored (i.e. age of onset of alcohol consumption, number of BD episodes in the last 6 months).

\section{DISCUSSION}

The main objective of this study was to investigate the link between $\mathrm{BD}$ and inhibitory control differences, with special consideration to the relationship between response inhibition and alcohol-related processing. We first analyzed the association between $\mathrm{BD}$ and behavioral performance in an alcohol-cued Go/ NoGo task. We then explored the task-related neural correlates for both BDs and controls. Finally, we considered if there were differences in neural activity in BDs, relative to controls, when exerting inhibitory control to alcohol-related cues.

Consistent with most of the previous studies using $\mathrm{Go} / \mathrm{NoGo}$ tasks in BDs $(43,67-72)$, we did not find behavioral differences related to $\mathrm{BD}$ in the examined response inhibition indices (i.e. FA) (irrespective of stimulus content). Furthermore, when alcohol cues were analyzed separately from non-alcohol cues, no significant differences in performance between BDs and $\mathrm{CN}$ were found. This finding is in line with a recent ERPs study from our group (54) and with previous studies reporting no differences in the number of FA (51-53, 55, 56), although some others have found an alcohol-cuespecific impairment of response inhibition (50).

In line with our hypothesis, the present neuroimaging results revealed an increased BOLD response in the bilateral IFG extending to the anterior insula (BA 47), in BDs compared to controls during successful inhibition trials, a region usually involved in response inhibition tasks $(39,73-75)$. As proposed by Aron and Poldrack (73), the inferior frontal cortex (IFC) modulates the interaction between the pre-supplementary motor area and the subthalamic nucleus (STN) within the neural network of response inhibition. Specifically, IFC sends excitatory impulses to the STN via the "hyperdirect" pathway and the STN sends excitatory output to the globus pallidus, which results in thalamus inhibition $(76,77)$. Looking at the characteristics of this neural circuitry, the increased activity in the IFG in the BD group could be interpreted as a greater recruitment of neural resources to successfully inhibit a response. Therefore, the differences observed in this region could be interpreted as part of a compensatory mechanism to attenuate the impact of abnormal brain activity on performance, in line with previous fMRI studies showing that BD is associated with increased neural activation, in the absence of behavioral impairments, during successful inhibition $(43,56)$.

TABLE 4 | Regions showing significant group differences (BD > CN) in BOLD response to successful inhibition.

\begin{tabular}{|c|c|c|c|c|c|c|c|c|}
\hline Contrast & Region (BA) & Side & $P$ (FWE)* & $x(\mathbf{m m})$ & $y(m m)$ & $\mathrm{z}(\mathrm{mm})$ & $\mathbf{k}$ & $t$ \\
\hline \multirow[t]{2}{*}{ NoGo > Go } & IFG/Insula (47) & Right & 0.031 & 34 & 34 & -6 & 74 & 3.64 \\
\hline & IFG/Insula (47) & Left & 0.018 & -30 & 16 & -2 & 114 & 3.30 \\
\hline NoGo Alcohol > Go Non-Alcohol & IFG/Insula (47) & Right & 0.031 & 30 & 20 & -6 & 72 & 3.57 \\
\hline
\end{tabular}

$\mathrm{ROI}$ analyses were based on the coordinates informed in the meta-analysis by Criaud and Boulinguez (33).

*Small volume correction (FWE, $p<.05$ ). 
A

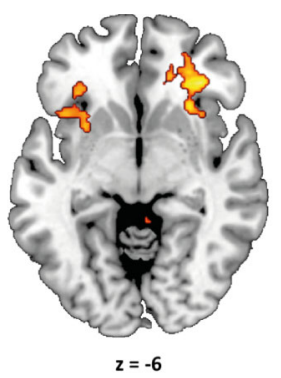

B

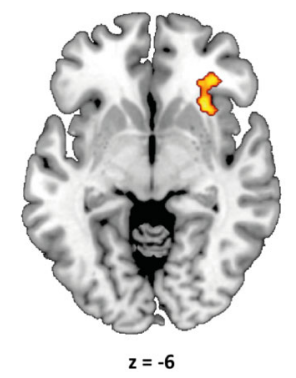

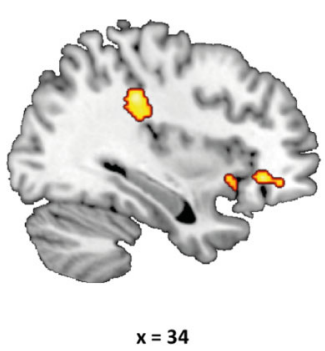

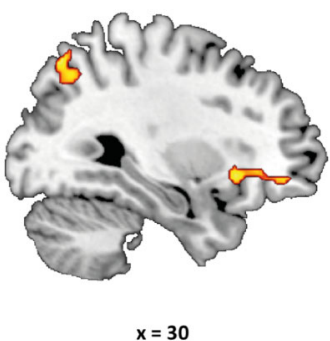

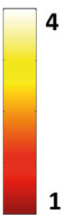

FIGURE 3 | Group differences (BD > CN) during successful inhibition. (A) Compared to controls, BDs showed a greater BOLD activity in the NoGo vs. Go contrast in the bilateral inferior frontal gyrus, extending to the anterior insula (BA 47) ( $p<.05$ FWE-small volume corrected). (B) BDs, in comparison with controls, showed a greater BOLD activity in the NoGo Alcohol vs. Go Non-Alcohol contrast in the right inferior frontal gyrus/anterior insula (BA 47 ) ( $p<.05$ FWE-small volume corrected). T-maps are thresholded at $\mathrm{p}<.005$ (uncorrected) and $\mathrm{k} \geq 150$ for display purposes only.

It is worth noting that while BD tends to be associated with increased neural response, AUD has been associated with reduced response in fronto-parietal regions (e.g., IFG, MFG, IPL) $(78,79)$. Further exploring this relationship, Worhunsky and colleages (80) have reported two different activity patterns associated with the escalation of maximum number of drinks consumed in a single episode (MaxDrinks). First, escalating drinkers showed a hyper-engagement of fronto-parietal control mechanisms during successful relative to unsuccessful inhibition trials compared to constant (low) drinkers. On the other hand, when the group of escalating drinkers was divided according to their MaxDrinks scores, a greater MaxDrinks was associated with reduced engagement of the fronto-parietal network. These findings thus suggest a transition, in terms of neural activation, from an initial consumption stage (related to hyperactivation) to a more problematic drinking (related to reduced engagement of neural resources).

Consistent with our second hypothesis and the findings reported by Ames et al. (56), we observed a greater activity in BDs (vs. controls) during response inhibition to alcohol-related stimuli. Specifically, BDs showed greater activity in the right IFG/ insula (BA 47) when inhibiting a response to alcohol stimuli (NoGo Alcohol > Go Non-Alcohol). However, no significant differences were observed when participants were asked to inhibit their response to non-alcohol stimuli (NoGo NonAlcohol > Go Alcohol). These findings suggest that response inhibition-related activity in the right IFG/insula seems to be modulated by the motivational salience of stimuli and highlight the role of this region in suppressing responses to substance- related cues. Also, these results are in agreement with previous studies, in the general population, showing that response inhibition could be modulated by the motivational content of stimuli (81-85). In particular, some of these works using fMRI to characterize the neural basis of this modulation reported increased neural activity of the IFG/insula in trials where a response to reward-related stimuli had to be inhibited $(82,85)$. It should be taking into account that the IFG and the anterior insula, besides being considered key regions for response inhibition, have been also proposed to be part of the salience network $(82,86,87)$ and, therefore, they may be involved in adjusting cognitive control to motivational demands of the context (86). In this regard, a metaanalysis has suggested that the right anterior insula would play an important role in detection of behaviorally relevant salient events, whereas the right IFG would be more involved in exerting inhibitory control (36). Therefore, it is possible that the higher activity observed in $\mathrm{BDs}$ in the right BA 47 is pointing to the presence of differences associated with the alcohol consumption pattern in the interaction between cognitive control and salience detection processes.

The current research extends prior results about BD-related anomalies in inhibitory control mechanisms and provides new evidence about increased IFG/insula activity, a key region for inhibitory control, during response inhibition to alcohol-related stimuli. Some limitations of the present study should be noted. First, the lack of assessment before participants engaged in $\mathrm{BD}$ prevents us from establishing potential pre-existing differences between groups that may explain the observed results, as indicated by previous investigations $(43,88,89)$. A future follow-up will 
allow us to deepen the relationship between $\mathrm{BD}$ pattern and neural anomalies in frontal regions and to explore if these early neural differences may subtend the transition from recreational to pathological consumption patterns. Second, in contrast with how Go/NoGo tasks are typically designed to be performed in behavioral experiments, the characteristics of the hemodynamic response led us to employ a relatively slow and unpredictable stimulus presentation which could reduce the prepotent tendency to respond. Therefore, this type of approach may be less sensitive for assessing behavioral differences and it should be taken into account when explaining the lack of differences between the groups. Third, similarly to previous studies [e.g. $(56,90)]$, our task involves a much more demanding cognitive context than classic Go/NoGo tasks, with attention, stimulus categorization and response selection processes being highly intertwined, so research findings should be interpreted with this limitation in mind. One final limitation should be noted: neither individual preferences nor potential differences in familiarity of the employed images were addressed in the present study.

In summary, our results revealed that young BDs showed increased frontal activity, relative to controls, during successful inhibition trials in an alcohol-cued Go/NoGo task, despite a lack of behavioral differences between groups. These findings provide new evidence about the role of the IFG, extending to the anterior insula, as an important region to explore neural differences associated with $\mathrm{BD}$, as well as suggest a specific involvement of this region in withholding a prepotent response to stimuli with alcohol-related content. At a more clinical level, our study provides subclinical information in a healthy population, without evidence of behavioral problems, which highlights the risk of this form of consumption. In addition, this investigation emphasizes the relevance of assessing the cognitive processes of interest using specific substance-related cues to better understand the relationship between those processes and the alcohol consumption pattern, and provides useful information to contribute to the development of future prevention strategies as suggested by studies focused on inhibitory control training and cognitive bias modification (see 91 for an insightful review of neuroscience findings and treatment programs).

\section{DATA AVAILABILITY STATEMENT}

The datasets generated for this study are available on request to the corresponding author.

\section{REFERENCES}

1. Kraus L, Nociar A. ESPAD report 2015: results from the European school survey project on alcohol and other drugs European Monitoring Centre for Drugs and Drug Addiction Luxembourg: European Monitoring Centre for Drugs and Drug Addiction (2016).

2. Abuse S. Mental Health Services Administration. Key Substance Use and Mental Health Indicators in the United States: Results From the 2016 National Survey on Drug Use and Health. In: Subst Abus Ment Heal Serv Adm. Rockville, MD: Center for Behavioral Health Statistics and Quality (2017).

\section{ETHICS STATEMENT}

The studies involving human participants were reviewed and approved by Bioethics Committee of the Universidade de Santiago de Compostela. The patients/participants provided their written informed consent to participate in this study.

\section{AUTHOR CONTRIBUTIONS}

FC, SD, SR, and MC designed the study. SS-S and JP-G participated in the data collection. MC was responsible for sample selection. SD and SR designed the experimental task. SS-S analyzed the data. FC, SD, and SS-S interpreted the data. SS-S wrote the article. All authors contributed to the article and approved the submitted version.

\section{FUNDING}

This investigation was supported by grants from the Spanish Ministerio de Sanidad, Servicios Sociales e Igualdad, Plan Nacional sobre Drogas (PNSD 2015/034), Ministerio de Economía y Competitividad (PSI2015-70525-P) co-funded for European Regional Development Fund and Xunta de Galicia (GRC ED431C 2017/06). SS-S was supported by a predoctoral fellowship from the Spanish Ministerio de Economía y Competitividad (BES-2016-076298). JP-G was supported by the FPU program from the Spanish Ministerio de Educación, Cultura y Deporte (FPU16/01573).

\section{ACKNOWLEDGMENTS}

We thank to the personnel of the Radiology Service of the Clinical University Hospital of Santiago de Compostela (CHUS) for technical assistance in MRI data acquisition.

\section{SUPPLEMENTARY MATERIAL}

The Supplementary Material for this article can be found online at: https://www.frontiersin.org/articles/10.3389/fpsyt.2020.00535/ full\#supplementary-material

3. Rehm J, Mathers C, Popova S, Thavorncharoensap M, Teerawattananon Y, Patra J. Global burden of disease and injury and economic cost attributable to alcohol use and alcohol-use disorders. Lancet (2009) 373:2223-33. doi: 10.1016/S0140-6736(09)60746-7

4. Organization WH. Global status report on alcohol and health 2018. Geneva, Switzerland: World Health Organization (2018). Available at: https://www. who.int/substance_abuse/publications/global_alcohol_report/en/.

5. Grant J, Scherrer J, Lynskey M, Lyons M, Eisen S, Tsuang M, et al. Adolescent alcohol use is a risk factor for adult alcohol and drug dependence: evidence from a twin design. Psychol Med (2006) 36:109-18. doi: 10.1017/S0033291705006045 
6. Newton-Howes G, Boden JM. Relation between age of first drinking and mental health and alcohol and drug disorders in adulthood: evidence from a 35-year cohort study. Addiction (2016) 111:637-44. doi: 10.1111/add.13230

7. Bonomo Y, Bowes G, Coffey C, Carlin J, Patton G. Teenage drinking and the onset of alcohol dependence: a cohort study over seven years. Addiction (2004) 99:1520-8. doi: 10.1111/j.1360-0443.2004.00846.x

8. Hingson RW, Heeren T, Winter MR. Age at Drinking Onset and Alcohol Dependence: Age at Onset, Duration, and Severity. Arch Pediatr Adolesc Med (2006) 160:739-46. doi: 10.1001/archpedi.160.7.739

9. Grant BF, Dawson DA. Age at onset of alcohol use and its association with DSM-IV alcohol abuse and dependence: results from the national longitudinal alcohol epidemiologic survey. J Subst Abuse (1997) 9:103-10. doi: 10.1016/S0899-3289(97)90009-2

10. National Institute of Alcohol Abuse and Alcoholism. NIAAA Council approves definition of binge drinking. In: NIAAA Newsletter, ed G. Roa (Bethesda, MD: Office of Research Translation and Communications, NIAAA, NIH, DHHS), 3. http://pubs.niaaa.nih.gov/publications/Newsletter/ winter2004/Newsletter_Number3.pdf.

11. Carbia C, López-Caneda E, Corral M, Cadaveira F. A systematic review of neuropsychological studies involving young binge drinkers. Neurosci Biobehav Rev (2018) 90:332-49. doi: 10.1016/J.NEUBIOREV.2018.04.013

12. Cservenka A, Brumback T. The Burden of Binge and Heavy Drinking on the Brain: Effects on Adolescent and Young Adult Neural Structure and Function. Front Psychol (2017) 8:1111. doi: 10.3389/fpsyg.2017.01111

13. Petit G, Maurage P, Kornreich C, Verbanck P, Campanella S. Binge drinking in adolescents: A review of neurophysiological and neuroimaging research. Alcohol Alcohol (2014) 49:198-206. doi: 10.1093/alcalc/agt172

14. Crabbe JC, Harris RA, Koob GF. Preclinical studies of alcohol binge drinking. Ann N Y Acad Sci (2011) 1216:24-40. doi: 10.1111/j.17496632.2010.05895.x

15. Wechsler H, Davenport A, Dowdall G, Moeykens B, Castillo S. Health and behavioral consequences of binge drinking in college: A national survey of students at 140 campuses. JAMA (1994) 272:1672-7. doi: 10.1001/ jama.1994.03520210056032

16. Crews F, Braun C, Hoplight B, Switzer IIIR, Knapp D. Binge ethanol consumption causes differential brain damage in young adolescent rats compared with adult rats. Alcohol Clin Exp Res (2000) 24:1712-23. doi: 10.1111/j.1530-0277.2000.tb01973.x

17. Jones SA, Lueras JM, Nagel BJ. Effects of binge drinking on the developing brain: studies in humans. Alcohol Res. Curr. Rev. (2018) 39:87-96.

18. Fuhrmann D, Knoll LJ, Blakemore S-J. Adolescence as a Sensitive Period of Brain Development. Trends Cognit Sci (2015) 19:558-66. doi: 10.1016/ J.TICS.2015.07.008

19. Giedd J. The Teen Brain: Insights from Neuroimaging. J Adolesc Heal (2008) 42:335-43. doi: 10.1016/J.JADOHEALTH.2008.01.007

20. Casey BJ, Jones RM, Hare TA. The Adolescent Brain. Ann N Y Acad Sci (2008) 1124:111-26. doi: 10.1196/annals.1440.010

21. Luna B, Padmanabhan A, O'Hearn K. What has fMRI told us about the development of cognitive control through adolescence? Brain Cognit (2010) 72:101-13. doi: 10.1016/J.BANDC.2009.08.005

22. Jacobus J, Tapert SF. Neurotoxic effects of alcohol in adolescence. Annu Rev Clin Psychol (2013) 9:703-21. doi: 10.1146/annurev-clinpsy-050212-185610

23. Squeglia L, Gray K. Alcohol and Drug Use and the Developing Brain. Curr Psychiatry Rep (2016) 18:46. doi: 10.1007/s11920-016-0689-y

24. Carter AC, Brandon KO, Goldman MS. The college and noncollege experience: A review of the factors that influence drinking behavior in young adulthood. J Stud Alcohol Drugs (2010) 71:742-50. doi: 10.15288/jsad.2010.71.742

25. Schulenberg JE, Maggs JL. A developmental perspective on alcohol use and heavy drinking during adolescence and the transition to young adulthood. $J$ Stud Alcohol (2002) s14:54-70. doi: 10.15288/jsas.2002.s14.54

26. Goldstein RZ, Volkow ND. Dysfunction of the prefrontal cortex in addiction: neuroimaging findings and clinical implications. Nat Rev Neurosci (2011) 12:652-69. doi: $10.1038 / \mathrm{nrn} 3119$

27. Goldstein RZ, Volkow ND. Drug addiction and Its underlying neurobiological basis: neuroimaging evidence for the involvement of the frontal cortex. Am J Psychiatry (2002) 159:1642-52. doi: 10.1176/appi.ajp.159.10.1642

28. Wiers RW, Bartholow BD, van den Wildenberg E, Thush C, Engels RCME, Sher KJ, et al. Automatic and controlled processes and the development of addictive behaviors in adolescents: A review and a model. Pharmacol Biochem Behav (2007) 86:263-83. doi: 10.1016/J.PBB.2006.09.021

29. Zilverstand A, Huang AS, Alia-Klein N, Goldstein RZ. Neuroimaging impaired response inhibition and salience attribution in human drug addiction: a systematic review. Neuron (2018) 98:886-903. doi: 10.1016/ j.neuron.2018.03.048

30. Noël X, Bechara A, Brevers D, Verbanck P, Campanella S. Alcoholism and the Loss of Willpower. J Psychophysiol (2010) 24:240-8. doi: 10.1027/0269-8803/ a000037

31. Lannoy S, Billieux J, Maurage P. Beyond inhibition: A dual-process perspective to renew the exploration of binge drinking. Front Hum Neurosci (2014) 8:405. doi: 10.3389/fnhum.2014.00405

32. Stevens MC, Kiehl KA, Pearlson GD, Calhoun VD. Functional neural networks underlying response inhibition in adolescents and adults. Behav Brain Res (2007) 181:12-22. doi: 10.1016/j.bbr.2007.03.023

33. Criaud M, Boulinguez P. Have we been asking the right questions when assessing response inhibition in go/no-go tasks with fMRI? A meta-analysis and critical review. Neurosci Biobehav Rev (2013) 37:11-23. doi: 10.1016/ j.neubiorev.2012.11.003

34. Simmonds DJ, Pekar JJ, Mostofsky SH. Meta-analysis of Go/No-go tasks demonstrating that fMRI activation associated with response inhibition is task-dependent. Neuropsychologia (2008) 46:224-32. doi: 10.1016/ J.NEUROPSYCHOLOGIA.2007.07.015

35. Swick D, Ashley V, Turken U. Are the neural correlates of stopping and not going identical? Quantitative meta-analysis of two response inhibition tasks. Neuroimage (2011) 56:1655-65. doi: 10.1016/j.neuroimage.2011.02.070

36. Cai W, Ryali S, Chen T, Li C-SR, Menon V. Dissociable roles of right inferior frontal cortex and anterior insula in inhibitory control: evidence from intrinsic and task-related functional parcellation, connectivity, and response profile analyses across multiple datasets. J Neurosci (2014) 34:14652-67. doi: 10.1523/ JNEUROSCI.3048-14.2014

37. Zhang R, Geng X, Lee TMC. Large-scale functional neural network correlates of response inhibition: an fMRI meta-analysis. Brain Struct Funct (2017) 222:3973-90. doi: 10.1007/s00429-017-1443-x

38. Levy BJ, Wagner AD. Cognitive control and right ventrolateral prefrontal cortex: reflexive reorienting, motor inhibition, and action updating. Ann N Y Acad Sci (2011) 1224:40-62. doi: 10.1111/j.1749-6632.2011.05958.x

39. Aron AR, Robbins TW, Poldrack RA. Inhibition and the right inferior frontal cortex: one decade on. Trends Cognit Sci (2014) 18:177-85. doi: 10.1016/ j.tics.2013.12.003

40. Luijten M, Machielsen MWJ, Veltman DJ, Hester R, de Haan L, Franken IHA. Systematic review of ERP and fMRI studies investigating inhibitory control and error processing in people with substance dependence and behavioural addictions. J Psychiatry Neurosci (2014) 39:149-69. doi: 10.1503/jpn.130052

41. Smith J, Mattick R, Jamadar S, Iredale J. Deficits in behavioural inhibition in substance abuse and addiction: A meta-analysis. Drug Alcohol Depend (2014) 145:1-33. doi: 10.1016/J.DRUGALCDEP.2014.08.009

42. López-Caneda E, Rodríguez Holguín S, Cadaveira F, Corral M, Doallo S. Impact of alcohol use on inhibitory control (and vice versa) during adolescence and young adulthood: a review. Alcohol Alcohol (2014) 49:17381. doi: $10.1093 /$ alcalc/agt168

43. Wetherill RR, Squeglia L, Yang TT, Tapert SF. A longitudinal examination of adolescent response inhibition: neural differences before and after the initiation of heavy drinking. Psychopharmacol (2013) 230:663-71. doi: 10.1007/s00213-013-3198-2

44. Whelan R, Watts R, Orr CA, Althoff RR, Artiges E, Banaschewski T, et al. Neuropsychosocial profiles of current and future adolescent alcohol misusers. Nature (2014) 512:185-9. doi: 10.1038/nature13402

45. Campanella S, Absil J, Carbia Sinde C, Schroder E, Peigneux P, Bourguignon $\mathrm{M}$, et al. Neural correlates of correct and failed response inhibition in heavy versus light social drinkers: an fMRI study during a go/no-go task by healthy participants. Brain Imaging Behav (2017) 11:1796-811. doi: 10.1007/s11682016-9654-y

46. Schacht JP, Anton RF, Myrick H. Functional neuroimaging studies of alcohol cue reactivity: a quantitative meta-analysis and systematic review. Addict Biol (2012) 18:121-33. doi: 10.1111/j.1369-1600.2012.00464.x

47. Brumback T, Squeglia L, Jacobus J, Pulido C, Tapert S, Brown SA. Adolescent heavy drinkers' amplified brain responses to alcohol cues decrease over one 
month of abstinence. Addict Behav (2015) 46:45-52. doi: 10.1016/ j.addbeh.2015.03.001

48. Ames SL, Grenard JL, He Q, Stacy AW, Wong SW, Xiao L, et al. Functional imaging of an alcohol-Implicit Association Test (IAT). Addict Biol (2014) 19:467-81. doi: 10.1111/adb.12071

49. Dager AD, Anderson BM, Rosen R, Khadka S, Sawyer B, Jiantonio-Kelly RE, et al. Functional magnetic resonance imaging (fMRI) response to alcohol pictures predicts subsequent transition to heavy drinking in college students. Addiction (2014) 109:585-95. doi: 10.1111/add.12437

50. Czapla M, Simon JJ, Friederich H-C, Herpertz SC, Zimmermann P, Loeber S. Is binge drinking in young adults associated with an alcohol-specific impairment of response inhibition? Eur Addict Res (2015) 21:105-13. doi: $10.1159 / 000367939$

51. Lannoy S, Maurage P, D’Hondt F, Billieux J, Dormal V. Executive impairments in binge drinking: evidence for a specific performancemonitoring difficulty during alcohol-related processing. Eur Addict Res (2018) 24:118-27. doi: 10.1159/000490492

52. Kreusch F, Vilenne A, Quertemont E. Response inhibition toward alcoholrelated cues using an alcohol go/no-go task in problem and non-problem drinkers. Addict Behav (2013) 38:2520-8. doi: 10.1016/j.addbeh.2013.04.007

53. Watson TD, Newton-Mora M, Pirkle J. Event-related potential correlates of processing alcohol-related pictures in young adult binge drinkers. Am J Drug Alcohol Abuse (2016) 42:77-87. doi: 10.3109/00952990.2015.1099660

54. Blanco-Ramos J, Cadaveira F, Folgueira-Ares R, Corral M, Rodriguez Holguin S. Electrophysiological Correlates of an Alcohol-Cued Go/NoGo Task: A Dual-Process Approach to Binge Drinking in University Students. Int $J$ Environ Res Public Health (2019) 16(22):4550. doi: 10.3390/ijerph16224550

55. Lannoy S, Dormal V, Billieux J, Brion M, D’Hondt F, Maurage P. A dualprocess exploration of binge drinking: Evidence through behavioral and electrophysiological findings. Addict Biol (2018) 1:1-10. doi: 10.1111/ adb. 12685

56. Ames SL, Wong SW, Bechara A, Cappelli C, Dust M, Grenard JL, et al. Neural correlates of a Go/NoGo task with alcohol stimuli in light and heavy young drinkers. Behav Brain Res (2014) 274:382-9. doi: 10.1016/J.BBR.2014.08.039

57. Varela J, Braña T, Real E, Rial A, Validación empírica do AUDIT. (Cuestionario de Identificación dos Trastornos debido ó consumo de alcohol) na poboación xeral galega. In: Conselleria De Sanidad-Sergas: Xunta de Galicia, Santiago de Compostela, Spain (2005).

58. Saunders JB, Aasland OG, Babor TF, de la Fuente JR, Grant M. Development of the Alcohol Use Disorders Identification Test (AUDIT): WHO collaborative project on early detection of persons with harmful alcohol consumption-II. Addiction (1993) 88:791-804. doi: 10.1111/j.13600443.1993.tb02093.x

59. Shiffman S, Waters AJ, Hickcox M. The Nicotine Dependence Syndrome Scale: A multidimensional measure of nicotine dependence. Nicotine Tob Res (2004) 6:327-48. doi: 10.1080/1462220042000202481

60. Becoña E, Nogueiras L, Flórez G, Álvarez S, Vázquez D. Propiedades psicométricas de la Escala del Síndrome de Dependencia de la Nicotina (NDSS) en una muestra de fumadores que solicitan tratamiento por su dependencia del alcohol. Adicciones (2010) 22:37-50. doi: 10.20882/ adicciones. 213

61. Legleye S, Karila L, Beck F, Reynaud M. Validation of the CAST, a general population Cannabis Abuse Screening Test. J Subst Use (2007) 12:233-42. doi: $10.1080 / 14659890701476532$

62. Cuenca-Royo AM, Sánchez-Niubó A, Forero CG, Torrens M, Suelves JM, Domingo-Salvany A. Psychometric properties of the CAST and SDS scales in young adult cannabis users. Addict Behav (2012) 37:709-15. doi: 10.1016/ j.addbeh.2012.02.012

63. Sobell LC, Sobell MB. Alcohol timeline followback users" manual. Toronto: Addict Res Found (1995).

64. González de Rivera JL, Derogatis LR, De las Cuevas C, Gracia Marco R, Rodríguez-Pulido F, Henry-Benitez M, et al. The Spanish version of the SCL90-R. Normative data in the general population. Towson, MD: Clin Psychom Res (1989).

65. Pronk T, van Deursen DS, Beraha EM, Larsen H, Wiers RW. Validation of the Amsterdam Beverage Picture Set: A controlled picture set for cognitive bias measurement and modification paradigms. Alcohol Clin Exp Res (2015) 39:2047-55. doi: 10.1111/acer.12853
66. Nobre AC, Coull JT, Maquet P, Frith CD, Vandenberghe R, Mesulam MM. Orienting attention to locations in perceptual versus mental representations. $J$ Cognit Neurosci (2004) 16:363-73. doi: 10.1162/089892904322926700

67. López-Caneda E, Cadaveira F, Crego A, Gómez-Suárez A, Corral M, Parada $M$, et al. Hyperactivation of right inferior frontal cortex in young binge drinkers during response inhibition: a follow-up study. Addiction (2012) 107:1796-808. doi: 10.1111/j.1360-0443.2012.03908.x

68. Franken IHA, Luijten M, van der Veen FM, van Strien JW. Cognitive control in young heavy drinkers: An ERP study. Drug Alcohol Depend (2017) 175:7783. doi: $10.1016 /$ j.drugalcdep.2017.01.036

69. Lannoy S, D’Hondt F, Dormal V, Billieux J, Maurage P. Electrophysiological correlates of performance monitoring in binge drinking: Impaired errorrelated but preserved feedback processing. Clin Neurophysiol (2017) 128:2110-21. doi: 10.1016/j.clinph.2017.08.005

70. Henges AL, Marczinski CA. Impulsivity and alcohol consumption in young social drinkers. Addict Behav (2012) 37:217-20. doi: 10.1016/ J.ADDBEH.2011.09.013

71. Moreno M, Estevez AF, Zaldivar F, Montes JMG, Gutierrez-Ferre VE, Esteban $\mathrm{L}$, et al. Impulsivity differences in recreational cannabis users and binge drinkers in a university population. Drug Alcohol Depend (2012) 124:355-62. doi: 10.1016/j.drugalcdep.2012.02.011

72. Cohen-Gilbert JE, Nickerson LD, Sneider JT, Oot EN, Seraikas AM, Rohan ML, et al. College binge drinking associated with decreased frontal activation to negative emotional distractors during Inhibitory Control. Front Psychol (2017) 8:1650. doi: 10.3389/fpsyg.2017.01650

73. Aron AR, Poldrack RA. Cortical and subcortical contributions to Stop Signal response inhibition: role of the subthalamic nucleus. J Neurosci (2006) 26:2424-33. doi: 10.1523/JNEUROSCI.4682-05.2006

74. Chikazoe J, Jimura K, Asari T, Yamashita K, Morimoto H, Hirose S, et al. Functional dissociation in right inferior frontal cortex during performance of Go/No-Go task. Cereb Cortex (2008) 19:146-52. doi: 10.1093/cercor/ bhn065

75. Steele VR, Aharoni E, Munro GE, Calhoun VD, Nyalakanti P, Stevens MC, et al. A large scale $(\mathrm{N}=102)$ functional neuroimaging study of response inhibition in a Go/NoGo task. Behav Brain Res (2013) 256:529-36. doi: 10.1016/j.bbr.2013.06.001

76. Aron AR. From reactive to proactive and selective control: developing a richer model for stopping inappropriate responses. Biol Psychiatry (2011) 69:e55-68. doi: 10.1016/j.biopsych.2010.07.024

77. Forstmann BU, Alkemade A. The Neuroanatomy and Neurochemistry of Response Inhibition. In: Egner T, editor. The Wiley Handbook of Cognitive Control Wiley Online Books. (2017) p. 274. doi: 10.1002/ 9781118920497.ch16

78. Claus ED, Feldstein Ewing SW, Filbey FM, Hutchison KE. Behavioral control in alcohol use disorders: relationships with severity. J Stud Alcohol Drugs (2013) 74:141-51. doi: 10.15288/jsad.2013.74.141

79. Ahmadi A, Pearlson GD, Meda SA, Dager A, Potenza MN, Rosen R, et al. Influence of alcohol use on neural response to Go/No-Go task in college drinkers. Neuropsychopharmacology (2013) 38:2197-208. doi: 10.1038/ npp.2013.119

80. Worhunsky PD, Dager AD, Meda SA, Khadka S, Stevens MC, Austad CS, et al. A preliminary prospective study of an escalation in "maximum daily drinks", fronto-parietal circuitry and impulsivity-related domains in young adult drinkers. Neuropsychopharmacology (2016) 41:1637-47. doi: 10.1038/ npp. 2015.332

81. Boehler CN, Hopf J-M, Stoppel CM, Krebs RM. Motivating inhibition reward prospect speeds up response cancellation. Cognition (2012) 125:498503. doi: 10.1016/j.cognition.2012.07.018

82. Boehler CN, Schevernels H, Hopf J-M, Stoppel CM, Krebs RM. Reward prospect rapidly speeds up response inhibition via reactive control. Cognit Affect Behav Neurosci (2014) 14:593-609. doi: 10.3758/s13415014-0251-5

83. Freeman SM, Razhas I, Aron AR. Top-Down response suppression mitigates action tendencies triggered by a motivating stimulus. Curr Biol (2014) 24:2126. doi: 10.1016/j.cub.2013.12.019

84. Freeman SM, Aron AR. Withholding a reward-driven action: Studies of the rise and fall of motor activation and the effect of cognitive depletion. J Cognit Neurosci (2015) 28:237-51. doi: 10.1162/jocn_a_00893 
85. Wang Y, Braver TS, Yin S, Hu X, Wang X, Chen A. Reward improves response inhibition by enhancing attentional capture. Soc Cognit Affect Neurosci (2018) 14:35-45. doi: 10.1093/scan/nsy111

86. Seeley WW, Menon V, Schatzberg AF, Keller J, Glover GH, Kenna H, et al. Dissociable Intrinsic Connectivity Networks for Salience Processing and Executive Control. J Neurosci (2007) 27:2349-56. doi: 10.1523/ JNEUROSCI.5587-06.2007

87. Bressler SL, Menon V. Large-scale brain networks in cognition: emerging methods and principles. Trends Cognit Sci (2010) 14:277-90. doi: 10.1016/ j.tics.2010.04.004

88. Norman AL, Pulido C, Squeglia L, Spadoni AD, Paulus MP, Tapert SF. Neural activation during inhibition predicts initiation of substance use in adolescence. Drug Alcohol Depend (2011) 119:216-23. doi: 10.1016/ J.DRUGALCDEP.2011.06.019

89. O’Halloran L, Nymberg C, Jollans L, Garavan H, Whelan R. The potential of neuroimaging for identifying predictors of adolescent alcohol use initiation and misuse. Addiction (2016) 112:719-26. doi: 10.1111/add.13629

90. Czapla M, Baeuchl C, Simon JJ, Richter B, Kluge M, Friederich H-C, et al. Do alcohol-dependent patients show different neural activation during response inhibition than healthy controls in an alcohol-related fMRI go/no-go-task? Psychopharmacol (2017) 234:1001-15. doi: 10.1007/s00213-017-4541-9

91. Verdejo-Garcia A, Lorenzetti V, Manning V, Piercy H, Bruno R, Hester R, et al. A Roadmap for Integrating Neuroscience Into Addiction Treatment: A Consensus of the Neuroscience Interest Group of the International Society of Addiction Medicine. Front Psychiatry (2019) 10:877. doi: 10.3389/ fpsyt.2019.00877

Conflict of Interest: The authors declare that the research was conducted in the absence of any commercial or financial relationships that could be construed as a potential conflict of interest.

Copyright (c) 2020 Suárez-Suárez, Doallo, Pérez-Garcia, Corral, Rodríguez Holguín and Cadaveira. This is an open-access article distributed under the terms of the Creative Commons Attribution License (CC BY). The use, distribution or reproduction in other forums is permitted, provided the original author(s) and the copyright owner(s) are credited and that the original publication in this journal is cited, in accordance with accepted academic practice. No use, distribution or reproduction is permitted which does not comply with these terms. 